Resenhas 


\title{
ACERCA DE LA RACIONALIDAD Y LA IRRACIONALIDAD DE NUESTRAS DECISIONES
}

\author{
Rodrigo Mora ${ }^{\star}$
}

ARIELY, D. Predictably irrational: the hidden forces that shapes our decisions. [S.1.]: Harper Collins, 2009. 341 p.

\section{RESUMEN}

Tal como sugiere su nombre, este texto postula que el comportamiento humano es fundamentalmente irracional, esto es, está gobernado por aspectos emocionales difíciles de explicar de acuerdo a explicaciones lógicas. Esta "irracionalidad" esta, no obstante lejos de ser aleatoria y estrictamente personal, sino que corresponde a un patrón regular con ciertas leyes y principios. Más aún, tal irracionalidad comprende distintos ámbitos del comportamiento, desde los procesos detrás de la compra de bienes muebles o inmuebles a los que definen las acciones éticas de las personas.

Palabras-clave: conducta humana; irracionalidad; previsibilidad.

\section{About rationality and IRrationality OF OUR DECISIONS}

\begin{abstract}
As its title suggests, this book postulates that human behavior is fundamentally irrational, that is, driven by emotional factors that are difficult to understand for logical mind. This irrationality is, nonetheless, neither random or subjective, but to some extent predictable and rather universal. Furthermore, such irrational reasoning can be found at different levels, from the way in which people acquire small or large-scale goods (a TV set or a house respectively), to the way in which individuals make ethical decisions.
\end{abstract}

Keywords: human behavior, irrationality, predictability.

\footnotetext{
^Arquitecto. Departamento de Arquitectura, Universidad Técnica Federico Santa María. Avenida España, 1680, Valparaíso, Chile.

Correo electrónico: rodrigo.mora@usm.cl
} 
Predictably Irrational (que en español se podría traducir como "predeciblemente irracional"), es uno de esos libros que uno simplemente no puede dejar de leer. Esto no es poco decir, si consideramos que este es un libro cuyo contenido, a pesar de versar sobre la economía del comportamiento (y por ende de la economía, el management y el marketing, áreas que frecuentemente son abordadas a través de estudios de caso con un lenguaje ágil), tiene un tono más cercano a la ciencia que al periodismo.

Escrito por Dan Ariely, sicólogo y economista israelí nacionalizado estadounidense que actualmente se desempeña como Professor de Economía el Comportamiento del MIT, el libro se estructura en trece capítulos que abordan distintos aspectos de la conducta humana, desde la racionalidad económica hasta la conducta sexual, pasando por la definición de normas sociales de convivencia o la adscripción a preceptos éticos. Cada uno de estos capítulos es relativamente autónomo temáticamente, pero tienen como aspecto en común que las teorías sobre el comportamiento ofrecidas por Ariely son abordadas científicamente a través de la experimentación con personas.

La hipótesis central del texto es que la conducta humana ha sido a menudo mal entendida, en el sentido de que se la ha considerado como fundamentalmente "racional". Ariely sugiere en cambio que el comportamiento no es totalmente racional, es decir, no está regido por un cálculo preciso y distante de la relativa conveniencia de una opción sobre otra, sino más bien es arbitrario (lo que en definitiva quiere decir que es hasta cierto punto

irracional), aunque no menos coherente, es decir predecible. Es este hecho, la predictabilidad de lo irracional del comportamiento lo que hace interesante al texto, lo que lo hace pasar de una serie de anécdotas aisladas y lo convierten en una especie de tratado, aun disperso, sobre la conducta humana.

Ariely ofrece vasta evidencia para sustentar la idea de conducta sistemáticamente irracional. Por ejemplo, muestra que al momento de comprar un bien (por ejemplo, un televisor o incluso una casa), las personas no juzgan cada opción en forma independiente, sino en relación a las ofrecidas en el momento. Así, si por ejemplo queremos vender un televisor A, la política de precios más conveniente es ponerlo junto a uno más caro y otro más barato, por cuanto la mayoría de las personas buscarán acercarse a lo "adecuado", por sobre lo óptimo o más conveniente económicamente. En palabras del autor, "la mayoría de las personas no sabe lo que quiere a menos que lo vea en contexto".

Interesante es también la idea de Ariely sobre el poder del cero costo como estrategia de marketing (por ejemplo, regalar un producto cuando se compra otro), que impulsa a las personas a consumir productos aún cuando no los deseen o requieren. En la misma línea, el autor muestra como la valoración del dinero cambia según las circunstancias (estamos más dispuestos a gastar en algo que normalmente nos parecería muy caro o suntuario si esta compra se enmarca dentro de un gasto mucho mayor, un ejemplo típico son las compras en aeropuertos o la disposición a gastar en asientos de cuero al momento de adquirir un vehículo). 
Más allá de estas evidencias, de interés evidente pero quizás demasiado ligadas a lo episódico de la conducta, lo cierto es que el libro también ofrece ideas interesantes sobre la naturaleza humana profunda. La primera es la idea del rol de lo que Ariely llama normas sociales. Se sugiere acá que están normas son a menudo subvaloradas por economistas, a pesar de que estas normas permiten el surgimiento de redes de cooperación inmensas capaces de crear empresas de alta valorización económica (como por ejemplo los programas de código abierto como Linux). A juicio de Ariely, las normas sociales no solo son subvaloradas sino además incomprendidas por los directivos de empresas ("las normas sociales están enmarcadas en nuestra naturaleza social y nuestro deseo por pertenecer a una comunidad. Ellas con cálidas y son límites claros y no necesitan retribuciones instantáneas"). Esto lleva a que a menudo nos encontremos que una organización busque, en sus principios ser como una "gran familia", lo que a menudo despierta en sus empleados la adherencia a las normas que rigen este tipo de organizaciones (las normas sociales, que son más elásticas y por tanto más susceptibles a sacrificios por parte de quienes las adscriben). Sin embargo, llegado en momentos críticos a menudo las empresas recurren a las normas de mercado, de carácter rígido y universal, lo que puede hacer que los empleados sientas que han sido "traicionados". El resultado es una vuelta atrás difícil de reparar pues "una vez que las normas de mercado entras en ser consideradas por nosotros, las normas sociales desaparecen".

Algo similar sucede con el comportamiento ético (interesantes son los estudios con estudiantes de Harvard acá), cuyo respeto no está garantizado y más bien depende de un esfuerzo permanente por recordar las implicancias que esta conducta tiene para la comunidad toda. Por último, el libro ofrece ciertas estrategias para ser más felices que se derivan de las observaciones anteriores. "Mientras más tenemos, más queremos. La única cura es romper el ciclo de relatividad [en nuestras aspiraciones]"

En síntesis, quizás la virtud fundamental del libro es ofrecer una serie de teorías sobre la naturaleza última del comportamiento humano basada en evidencia vasta y real sobre éste. Un rol fundamental al respecto lo juega el tono del libro, que combina adecuadamente lo científico con lo periodístico. Como contrapartida, quizás la debilidad principal es que estas teorías no están agrupadas (todavía), en un todo coherente e identificable. Con todo, es un libro de ayuda para todos los interesados en entender las profundidades del comportamiento humano.

Recebido em: 07 de março de 2011 Aceito em: 22 de julho de 2011 